Edwards, S. \& Kumar, V. (1984) A survey of prescribing of psychotropic drugs in a Birmingham psychiatric hospital. British Journal of Psychiatry, 145, 502-507.

Famuyiwa, O. O. (1988) Psychotropic polypharmacy in Nigeria. The danger can be avoided and cost reduced. Tropical Doctor, 18, 7-11.

Gross, F. (1981) Drug utilisation therapy and practice. The present situation in Federal Republic of Germany. European Journal of Clinical Pharmacology, 19, 387-394.

Gureje, O., Chisholm, D., Kola, L., et al (2007) Cost-effectiveness of an essential mental health intervention package in Nigeria. World Psychiatry, 6, 42-48
Thompson, A., Sullivan, S. A., Barley, M., et al (2008) The DEBIT Trial: an intervention to reduce antipsychotic polypharmacy prescribing in adult psychiatric wards - a cluster randomized controlled trial. Psychological Medicine, 38, 705-715.

Xiang, Y.-T., Weng, Y.-Z., Leung, C-M., et al (2007a) Clinical and social determinants of use of depot antipsychotics for patients with schizophrenia in Hong Kong. Hong Kong Journal of Psychiatry, 16, 71-75.

Xiang, Y.-T., Weng, Y.-Z., Leung, C-M., et al (2007b) Exploring the clinical and social determinants of prescribing anticholinergic medication for Chinese patients with schizophrenia. Human Psychopharmacology, $22,173-180$

\title{
State of indigenous mental health in Australia - a colonial legacy?
}

\section{Sanil Rege MBBS MRCPsych FRANZCP}

Consultant Psychiatrist, Northern Sydney Central Coast Mental Health Service, Australia, email rege_1@yahoo.es

$$
T_{\text {che }}^{\text {he }}
$$
he Aboriginal culture of Australia is one of the oldest cultures on earth, dating back 50000 years. The Aboriginal and Torres Strait Islander (ATSI) people are the indigenous inhabitants of Australia, constituting $2.4 \%$ of the population. The health status of these 'First Australians' has been described as a source of national shame, with the life expectancy approximately 17 years lower than that of other Australians (Eades, 2000). This gap in life expectancy is also significantly larger than that of other countries with indigenous populations and a history of colonisation, such as the USA, Canada and New Zealand (Ring \& Firman, 1998). This paper offers an overview of the impact of colonisation and its subsequent influence on the social and emotional well-being of ATSI people.

\section{Culture and history}

Colonial domination .... is made possible by the negation of national reality, by new legal relations introduced by the occupying power, by the banishment of the natives and their customs to outlying districts by colonial society, by expropriation, and by the systematic enslaving of men and women. (Fanon, 1963)

Aboriginal mental health cannot be separated from its historical context. Australia was colonised by the British in 1788. At this time there were 300000 Aborigines with 250 distinct languages. Aboriginal society was collectivistic, with extended family clans and traditional kinship structures governed by a set of social laws, customs, rituals and cultural beliefs which differed from one clan to the other. Land was central to the concept of the Aboriginal self. The advent of the British led to the declaration of Australia as 'Terra Nullius' (no man's land), followed by several years of conflict, marginalisation and forced acculturation, with resultant loss of traditional society, religion, law, land and cultural identity. One of the most detrimental policies was the forcible removal of 'half-caste' Aboriginal children from their families and sending them away to work for non-indigenous people with the aim that they would, over time, 'merge' with the non-indigenous population. This began in the 19th century and became public policy in the 20th century; it was still in place as late as 1970. Many hundreds of thousands of children suffered psychological distress through loss of family and culture, physical and sexual abuse, exploitation and institutionalism (HEREOC, 1997). The catastrophic effects of this policy have been highlighted in the Bringing Them Home report, some of which include identity issues, lack of trust and intimacy, delinquency, high rates of depression and suicide, and poor parenting and relationships, thus establishing a vicious circle, producing the 'stolen generations'. This policy, which has been described as genocide (Totten et al, 2007), continues to exert its influence on the psychological well-being of Aboriginal people through intergenerational transmission. It was only in 1967 that Aboriginals were afforded the status of citizens of Australia; previously they came under the Flora and Fauna Act.

Aboriginals continue to maintain strong links to their traditional culture and lands. Data from the 2002 National Aboriginal and Torres Strait Islander Social Survey revealed that $54 \%$ identified with a clan or tribal group, $22 \%$ currently lived on traditional lands, $68 \%$ had participated in cultural events in last 12 months and 14\% did not speak English as their primary language (see http://abs.gov.au/ausstats/abs@.nsf/cat/4714.0).

\section{Social and emotional well-being of Aboriginal Australians}

Aboriginal concepts of mental health are holistic, as illustrated in the following quotation from the Ways Forward report on ATSI mental health:

Health does not just mean the physical well-being of the individual but refers to the social, emotional and cultural well-being of the whole community. This is a whole of life view and includes the cyclical concept of life-death-life. (Swan \& Raphael, 1995) 
This differs from the definition of health given by the World Health Organization (WHO), which does not include the cultural and spiritual dimensions. In view of this, the WHO in 1999 proposed a definition of health for indigenous peoples of the world that does encompass the spiritual, intellectual, physical and emotional domains.

There are significant cultural variations in the expression of psychiatric illness among Aboriginal people, which influences assessment, diagnosis and management. These variations stem from the fundamental difference in the concept of health, that is, a holistic concept as opposed to the Western mind-body dichotomy. Thus, Western models of mental illness do not always apply to Aboriginal illness beliefs and can lead to misdiagnosis and inappropriate treatment. Illness is often attributed to external forces linked to family, land, spirituality and culture, with healing proceeding through traditional methods underpinned by cultural explanatory models of illness. Many mental illnesses in Aboriginal people may fall under the DSM definitions of 'culture-bound syndromes' (Westerman, 2004).

Indigenous Australians are 1.5 times more likely than non-indigenous Australians to report at least one stressor, according to the Australian Bureau of Statistics General Social Survey (see http://www.abs.gov.au/ausstats/abs@.nsf/ cat/4159.0). The most common stressors are the death of a family member or close friend $(46 \%)$, serious illness or disability (31\%) and inability to get a job (27\%). The mortality rate from mental health conditions is twice that for other Australians. Half of all ATSI people who die are aged less than 50 years. This results in repeated grief for families, along with loss of significant elders to maintain the traditional culture. Their hospitalisation rates for mental illness are twice those of non-indigenous Australians (Centre for Mental Health, 2007).

Although the proportion of Aboriginals who drink is lower than that of the rest of the population, those who do drink do so at above recommended guidelines, in a binge-drinking pattern. They are also twice as likely to report being a recent drug user as non-indigenous Australians, with cannabis the main drug of misuse. Violence, child abuse and incarceration are more likely to be experienced by ATSI people and trends suggest that this may have become worse over the past decade (Australian Health Ministers' Advisory Council, 2006).

The poor mental health of ATSI people is due to a combination of genetic, historical, political, cultural and social causes. These include the intergenerational transmission of trauma, unresolved identity issues, political policies resulting in sociocultural dislocation and high mortality rates from physical illness resulting in high rates of grief and loss in communities. From a service point of view, indigenous people do not access mental health services at a level that reflects their needs and the main burden is therefore taken over by primary care services. The causes of poor access to mental health services are summarised in Box 1.

\section{Mental health policy}

The current mental health policy is based on the Social and Emotional Well Being Framework 2004-09 and the National Mental Health Plan 2003-08. It has been recognised that health policies need to acknowledge the trauma and grief resulting from past policies and that this should also be incorporated within their development. Furthermore, they should support self-determination, recognise historical and cultural diversities within communities and be based on culturally valid understandings of health. In addition, several other steps have been taken to acknowledge the grief and trauma experienced by ATSI people. These include the reconciliation policy, the Bringing Them Home report dedicated to the stolen generations, the 'Close the gap' policy aiming to close the life expectancy gap and, most recently, the apology on 12 February 2008 by the Prime Minister, Mr Kevin Rudd, on behalf of the federal government to the stolen generations for the past atrocities.

\section{The future}

Before colonisation, the Aboriginal people had an active lifestyle, with little indication of the high rates of obesity, diabetes, renal disease, hypertension and coronary heart disease that are so rife today (Jackson \& Ward, 1999). For a discussion of the causes of poor health and low life expectancy I would refer readers to Durie (2003).

Aboriginal mental health is currently in a dire situation; there are high mortality rates due to mental illness, high rates of violence, substance misuse and child sexual abuse, in the context of poor socio-economic conditions. There are no clear solutions, but it has been acknowledged that there should be a greater focus on improving access to mental health services. Mental health services need to work closely with Aboriginal communities as principal stakeholders in order to develop culturally sensitive mental health services (Box 2).

However, as proposed by Durie (2003), political and socioeconomic changes may be more important in changing the health status of ATSI people. Political policies continue to be controversial and perceived by many ATSI people as discriminatory and racist, with ongoing disputes over indigenous rights and sovereignty. On 21 June 2007, in response to a damning report about widespread child abuse, the federal government sent troops, police officers and medical teams to 73 indigenous communities in the Northern Territory, resulting in welfare payments being 'quarantined' and bans on alcohol and pornography introduced. There followed protests

Box 1 Barriers to mental health services

1 General attitude of mistrust due to past associations of health services with removal of children and discriminatory treatment perpetuated by current racism and negative staff attitudes

2 Limited 'mental health literacy' in Aboriginal communities

3 Inadequate Aboriginal mental health workforce

4 Relative poverty of Aboriginal people and geographical isolation

5 Culturally insensitive models of healthcare delivery

(e.g. failure to use a holistic model of health)

6 Inadequate awareness by mental health services of the historical, community and cultural factors related to Aboriginal mental health

7 Lack of necessary knowledge and skills among non-Aboriginal mental health clinicians to work effectively with aboriginal young people

Source: Centre for Mental Health (2007). 
Box 2 Components of a culturally sensitive mental health service for indigenous Australians

1 Increasing cultural competencies among mental health professionals (e.g. interviewing skills, cultural etiquette) to reduce the cultural disparity between client and practitioner

2 Developing and utilising culturally appropriate diagnostic tools (e.g. the Westerman Aboriginal Symptom Checklist, WASC)

3 Increasing mental health literacy by incorporating culturespecific models of illness in management

4 Utilising cultural consultants, Aboriginal mental health workers and community elders as standard practice throughout mental health services working with indigenous people

5 Incorporating culturally appropriate treatment options, which may include traditional methods of healing, at an appropriate level

Adapted from Westerman (2004).

throughout the country against the legislation, which has nonetheless been backed by the new government. The United Nations independent envoy, Professor James Anaya, was reported as saying on 27 August 2009 that Australia is breaching its international human rights obligations by continuing the Northern Territory intervention:

In my opinion, as currently configured and carried out, the emergency response is incompatible with Australia's obligations under the convention of elimination of forms of racial discrimination and the international convention on political rights. (See http://www.abc.net.au/news/stories/2009/08/27/ 2668915.htm)

Australia was also one of the four countries that voted against the Declaration of Rights of Indigenous Peoples (which sets out the individual and collective rights of the world's 370 million native peoples) adopted by the United Nations General Assembly in Septermber 2007, although 143 countries voted for it. (On 3 April 2009 Australia did in fact reverse its previous policy and backed the Declaration, which is, however, not legally binding.)
Without political cooperation, a collective change in the societal psyche acknowledging the trauma and grief, and without social inclusion, it is difficult to see how the current negative health status can be reversed. If the current trend persists, Australia is staring at the disappearance of one of the most ancient cultural heritages in the world.

\section{Acknowledgements}

I would like to thank LaVerne Bellear, Director of Aboriginal Health, Northern Sydney Central Coast Area Health Service, for her advice in preparing the manuscript.

\section{References}

Australian Health Ministers' Advisory Council (2006) Aboriginal and Torres Strait Islander Health Performance Framework Report 2006. AHMAC.

Centre for Mental Health (2007) NSW Aboriginal Mental Health and Well Being Policy 2006-2010. New South Wales Department of Health.

Durie, M. H. (2003) Health of indigenous peoples. BMJ, 326, 510-511.

Eades, S. J. (2000) Reconciliation, social equity and indigenous health A call for symbolic and material change. Medical Journal of Australia, 172, 468-469.

Fanon, F. (1963) The Wretched of the Earth (trans. C. Farrington). Grove Weidenfeld.

HEREOC (Human Rights and Equal Opportunity Commission) (1997) Bringing Them Home: The 'Stolen Children' Report. Available at http://www.humanrights.gov.au/social_justice/bth_report/index.html (accessed August 2009)

Jackson, R. L. \& Ward, J. E. (1999) Aboriginal health: why is reconciliation necessary? Medical Journal of Australia, 170, 437-440.

Ring, I. T. \& Firman, D. (1998) Reducing indigenous mortality in Australia: lessons from other countries. Medical Journal of Australia, 169, 528531.

Swan, P. \& Raphael, B. (1995) Ways Forward. National Consultancy Report on Aboriginal and Torres Strait Mental Health. Commonwealth of Australia, Canberra.

Totten, S., Bartrop, P. R. \& Jacobs, S. L. (2007) Dictionary of Genocide Greenwood Press.

Westerman, T. G. (2004) Engagement of indigenous clients in mental health services: what role do cultural differences play? Australian e-Journal for the Advancement of Mental Health, 3(3). Available at http://www.auseinet.com/journal/vol3iss3/westermaneditorial.pdf (accessed August 2009).

\section{College African Division's session at the WPA regional meeting}

From 22 to 24 October 2009, a regional meeting of the World Psychiatric Association (WPA) is due to take place, hosted jointly by the African Association of Psychiatrists and Allied Professionals (AAPAP) and the Association of Psychiatrists in Nigeria (APN), in Abuja, the capital city of Nigeria. The theme of the conference is 'Scaling Up and Reaching Down: Addressing Unmet Need For Service'. The sub-themes will focus on gender, poverty, HIV/AIDS and human rights.
It is certain to be a very special event, with psychiatrists and mental health workers expected from Africa, Europe, the USA and elsewhere. There will be a special Royal College of Psychiatrists session during the conference. There will be special programmes, such as a health policy roundtable, involving the ministers of health of countries in the region. There will also be a leadership training workshop for young psychiatrists, a training workshop on child and adolescent mental health, and a workshop on research methodology. Visitors will be able to enjoy guided tours of the scenic city of Abuja and surrounding areas. For more information, visit the conference website, http://www.nomadafrica.com/wpninfo. 